\title{
Optimal Timing for Hemoglobin Concentration Determination after Total Knee Arthroplasty: Day 1 versus Day 2
}

\author{
Mahdi Yacine Khalfaoui, MRCS ${ }^{1}$, Charles Godavitarne, MRCS $^{2}$, and Michael C P Wilkinson, MRCS ${ }^{2}$ \\ ${ }^{1}$ Department of Trauma and Orthopaedics, Salford Royal NHS Foundation Trust, Salford; ${ }^{2}$ Department of Trauma and Orthopaedics, King's College Hospital, London, \\ UK
}

Purpose: Postoperative hemoglobin $(\mathrm{Hb})$ determination remains an essential parameter for quantifying blood loss following total knee replacement (TKR) surgery and guiding transfusion practice. In this study we aimed to ascertain the optimal timing for Hb determination postoperatively and assess its relationship to serum hematocrit (Hct).

Materials and Methods: This was a retrospective cohort analysis of 61 consecutive patients undergoing preoperative, day 1 and day $2 \mathrm{Hb}$ and $\mathrm{Hct}$ concentration determination following TKR surgery. This was a single centre study in the United Kingdom.

Results: The mean fall in $\mathrm{Hb}$ concentration at day 1 was $2.9 \mathrm{~g} / \mathrm{dL}$ in comparison to $3.3 \mathrm{~g} / \mathrm{dL}$ at day 2 . This indicated a significant difference of $0.39 \mathrm{~g} / \mathrm{dL}(\mathrm{p}=0.023)$. A total of 5 patients required blood transfusions following day $2 \mathrm{Hb}$ determination. Postoperative Hct values varied in close relation with the $\mathrm{Hb}$ concentration with no significant differences demonstrated. Our study reveals a significant change between day 1 and day $2 \mathrm{Hb}$ concentrations following TKR surgery, with no significant differing information provided through Hct determination.

Conclusions: Our results support the use of delayed routine testing at day 2 following surgery as it is likely to more accurately reflect ongoing hidden blood loss into the joint cavity and within soft tissue planes.

Keywords: Knee, Arthroplasty, Blood loss, Hemoglobin, Hematocrit

\section{Introduction}

Total knee arthroplasty has long been associated with significant blood loss ${ }^{1}$. Blood transfusions are not uncommon in the immediate postoperative recovery period. A significant drop in hemoglobin $(\mathrm{Hb})$ following total knee replacement (TKR) can hinder rehabilitation during the critical initial recovery period and ultimately delay discharge ${ }^{2}$. Blood transfusions are indicated

Received June 30, 2016; Revised September 28, 2016;

Accepted September 29, 2016

Correspondence to: Mahdi Yacine Khalfaoui, MRCS

Department of Trauma and Orthopaedics, Salford Royal NHS

Foundation Trust, Stott Lane, Salford M6 8HD, UK

Tel: +44-7742-781020, Fax: +44-0161-206-1048

E-mail: Khalfaoui@doctors.org.uk

This is an Open Access article distributed under the terms of the Creative Commons Attribution Non-Commercial License (http://creativecommons.org/licenses/by-nc/4.0/) which permits unrestricted non-commercial use, distribution, and reproduction in any medium, provided the original work is properly cited. in those with a significant $\mathrm{Hb}$ drop, which places patients at risk of transfusion reactions. Minimising blood loss intraoperatively and postoperatively is therefore crucial for any orthopaedic surgeon and the subject of a significant volume of research across the years in the orthopaedic literature ${ }^{1-6)}$. Proven methods for minimising blood loss include: application of a tourniquet ${ }^{4)}$, meticulous operative technique ${ }^{1)}$, the use of anti-fibrinolytic agents ${ }^{2}$, the use of computer navigation ${ }^{5}$, and sealing of the intramedullary femoral $\mathrm{canal}^{6}$.

As well as blood loss dictating whether a postoperative transfusion is indicated, the $\mathrm{Hb}$ concentration immediately following surgery is equally influential. Hb thresholds used for determining when a transfusion is required vary significantly across the literature. Historically thresholds as high as $10 \mathrm{~g} / \mathrm{dL}$ were utilized ${ }^{7}$. However, more recently lower thresholds $(7 \mathrm{~g} / \mathrm{dL})$ have been incorporated into guidelines ${ }^{8}$. Current evidence suggests, such restrictive practice is as effective and in some cases superior in critically ill patients than using more traditional liberal transfusion strategies ${ }^{9,10}$. Preoperative $\mathrm{Hb}$ concentration is also a significant 
predictor for postoperative transfusion in knee arthroplasty ${ }^{11}$. It is therefore critical to determine preoperative $\mathrm{Hb}$ concentration as part of a routine work-up and treat reversible causes of anaemia prior to surgery.

With postoperative $\mathrm{Hb}$ concentration thresholds playing a critical role in directing transfusion strategies, and previous studies demonstrating significant variation in $\mathrm{Hb}$ and hematocrit $(\mathrm{Hct})$ concentrations according to the timing of blood collection in the medical literature ${ }^{12)}$, we set out to evaluate the optimal timing in the postoperative setting for determining $\mathrm{Hb}$ concentration following TKR. Furthermore, we wanted to investigate the role of the Hct level following surgery in order to determine any potential advantage in using this parameter for guiding transfusion practice.

\section{Materials and Methods}

This was a single centre retrospective cohort study. All patients undergoing a primary TKR at our centre between December 2012 and May 2014 were included in the study if a postoperative $\mathrm{Hb}$ concentration was determined at both days 1 and 2. Patients requiring earlier than day $1 \mathrm{Hb}$ testing due to clinical symptoms or requiring urgent postoperative transfusions were excluded from the study, as these were not deemed to be representative of routine cases.

The prosthetic implant used was the PFC sigma (DePuy Synthes, Warsaw, IN, USA). Prior to surgery, weight bearing radiographs were obtained, with templates produced for each case, to determine several factors including the canal entry point and implant sizing. All procedures were carried out with a tourniquet applied. The tourniquet was released after closure and application of dressings. Dressings remained in situ for the first 48 hours after the procedure. A closed suction drain was routinely used and removed at 24 hours following surgery in all patients. Antifibrinolytic agents and autologous blood transfusions were not routinely used in our patients during the study period and would only be considered in patients with hematological disorders following hematology recommendation. Routine transfusion practice was conducted according to local trust policy focusing on $\mathrm{Hb}$ concentration, patient comorbidities and postoperative symptomatology based on the British Committee for Standards in Hematology guidelines ${ }^{8}$.

Data was collected from the unit's electronic patient records system. The data extracted included the $\mathrm{Hb}$ concentration and Hct at the preoperative stage, day 1 and day 2 following surgery. Demographic data including patients' gender and age were also collected. Lastly, whether a patient required a blood transfusion or not following the day $2 \mathrm{Hb}$ determination was also recorded.

In the first part of our study, we analysed the $\mathrm{Hb}$ and Hct concentrations for differences between day 1 and day 2 samples. The paired Student $t$-test was used to compare the results across the 2 days. In the second part of our study, we compared the relative $\mathrm{Hb}$ and Hct changes at both days 1 and 2, to assess potential discrepancies between these two parameters and the effects of these. All data was collected using Microsoft Excel ver. 2010 (Microsoft, Redmond, WA, USA) and statistical tests were performed using STATA ver. 8.2 (StataCorp LP, College Station, TX, USA). A pvalue of $<0.05$ was deemed to represent a significant correlation.

\section{Results}

A total of 61 patients met both the inclusion and exclusion criteria set from 104 patients initially reviewed and were subsequently analysed in our study. There was a gender ratio of $46: 15$ with a female predominance. The mean age of subjects was 67.2 years (range, 41 to 89 years). The average preoperative $\mathrm{Hb}$ level in our patient cohort was $13.1 \mathrm{~g} / \mathrm{dL}$ (range, 9.6 to $16.2 \mathrm{~g} / \mathrm{dL}$ ) (Table 1). Our patients exhibited a mean drop in $\mathrm{Hb}$ concentration to $10.2 \mathrm{~g} / \mathrm{dL}$ and $9.8 \mathrm{~g} / \mathrm{dL}$ at days 1 and 2 , respectively. The average preoperative Hct was 0.395 (range, 0.302 to 0.515 ), falling to 0.309 and 0.294 at days 1 and 2, respectively. Our analysis revealed a significant drop in $\mathrm{Hb}$ concentration by $2.9 \mathrm{~g} / \mathrm{dL}$ at day 1 following surgery ( $\mathrm{p}=0.000$; $95 \%$ confidence interval [CI], 2.409 to 3.388 ) and $3.3 \mathrm{~g} / \mathrm{dL}$ at day 2 ( $\mathrm{p}=0.000 ; 95 \% \mathrm{CI}, 2.843$ to 3.830 ) across our entire cohort (Table 2). The change in Hb concentration at day 1 following surgery ranged from an increase of $0.9 \mathrm{~g} /$ $\mathrm{dL}$ to a fall by $7.5 \mathrm{~g} / \mathrm{dL}$. At day 2 , this ranged from an increase of 2.7 $\mathrm{g} / \mathrm{dL}$ to a fall of $8.1 \mathrm{~g} / \mathrm{dL}$.

Table 1. Description of the Hemoglobin (Hb) and Hematocrit (Hct) Values

\begin{tabular}{ccc}
\hline Variable & Mean (range) & Standard deviation \\
\hline Preoperative & & \\
$\mathrm{Hb}(\mathrm{g} / \mathrm{dL})$ & $13.1(9.6-16.2)$ & 1.44 \\
$\mathrm{Hct}$ & $0.4(0.3-0.5)$ & 0.04 \\
$\mathrm{Day} 1$ & & \\
$\mathrm{Hb}(\mathrm{g} / \mathrm{dL})$ & $10.2(7.2-15.6)$ & 1.75 \\
$\mathrm{Hct}$ & $0.3(0.2-0.5)$ & 0.06 \\
$\mathrm{Day} 2$ & & \\
$\mathrm{Hb}(\mathrm{g} / \mathrm{dL})$ & $9.8(6.1-14.5)$ & 1.73 \\
$\mathrm{Hct}$ & $0.3(0.2-0.4)$ & 0.05 \\
\hline
\end{tabular}


Table 2. Comparison of the Preoperative and Postoperative Hemoglobin (Hb) and Hematocrit (Hct) Differences

\begin{tabular}{ccccccc}
\hline \multirow{2}{*}{ Variable Preoperative } & \multicolumn{5}{c}{ Postoperative } \\
\cline { 3 - 7 } & & Day 1 & Day 2 & Difference & p-value & $95 \% \mathrm{CI}$ \\
\hline $\mathrm{Hb}$ & 13.1 & 10.2 & N/A & 2.9 & 0.00 & 2.41 to 3.39 \\
$(\mathrm{~g} / \mathrm{dL})$ & 13.1 & N/A & 9.8 & 3.3 & 0.00 & 2.84 to 3.83 \\
& $\mathrm{~N} / \mathrm{A}$ & 10.2 & 9.8 & 0.4 & 0.02 & 0.06 to 0.73 \\
$\mathrm{Hct}$ & 0.4 & 0.3 & $\mathrm{~N} / \mathrm{A}$ & 0.1 & 0.00 & 0.07 to 0.10 \\
& 0.4 & N/A & 0.3 & 0.1 & 0.00 & 0.09 to 0.12 \\
& $\mathrm{~N} / \mathrm{A}$ & 0.3 & 0.3 & 0.0 & 0.01 & 0.00 to 0.03 \\
\hline
\end{tabular}

CI: confidence interval, N/A: not applicable.

Table 3. Comparison of the Relative Changes Postoperatively in Hemoglobin $(\mathrm{Hb})$ and Hematocrit $(\mathrm{Hct})$

\begin{tabular}{cccccc}
\hline & $\mathrm{Hb}(\mathrm{g} / \mathrm{dL})$ & $\mathrm{Hct}$ & Difference & $\mathrm{p}$-value & $95 \% \mathrm{CI}$ \\
\hline Day 1 & 0.2 & 0.2 & 0.00 & 0.96 & -0.02 to 0.01 \\
Day 2 & 0.3 & 0.3 & 0.00 & 0.59 & -0.04 to 0.02 \\
\hline
\end{tabular}

CI: confidence interval.

A comparison between the mean day 1 and day $2 \mathrm{Hb}$ concentrations revealed a significant difference of $0.4 \mathrm{~g} / \mathrm{dL}$ ( $\mathrm{p}=0.023$; $95 \%$ CI, 0.056 to 0.729 ) (Table 2). This then led to a total of 5 patients requiring blood transfusions following the results of the day $2 \mathrm{Hb}$ concentration. Of the 5 patients requiring a blood transfusion following day $2 \mathrm{Hb}$ determination, 2 were indicated due to a $\mathrm{Hb}$ concentration of $<7 \mathrm{~g} / \mathrm{dL}$, and 3 of the patients were in the range of 7.0-9.0 g/dL with positive symptoms. On analyzing the days 1 and $2 \mathrm{Hb}$ concentrations, all patients who later required a blood transfusion were at the $9 \mathrm{~g} / \mathrm{dL}$ threshold or under at day 1 following surgery. The difference between preoperative and day $1 \mathrm{Hb}$ concentration did not reveal any specific pattern to predict which patients would go on to require a blood transfusion.

In the second part of our analysis, our results indicated that the serum Hct varied in close relation to the $\mathrm{Hb}$ concentration (Table 3). Scatter plots of $\mathrm{Hb}$ against Hct at both days 1 and 2 revealed a linear relationship confirming a similar trend in these parameters (Figs. 1 and 2). We demonstrated similar relative drops in both $\mathrm{Hct}$ and $\mathrm{Hb}$ levels with no significant differences at days 1 $(\mathrm{p}=0.962)$ and $2(\mathrm{p}=0.588)$.

\section{Discussion}

Studies addressing the timing for $\mathrm{Hb}$ determination following surgery remain scarce in the literature. To our knowledge, this is the first study addressing the optimal timing for $\mathrm{Hb}$ assessment

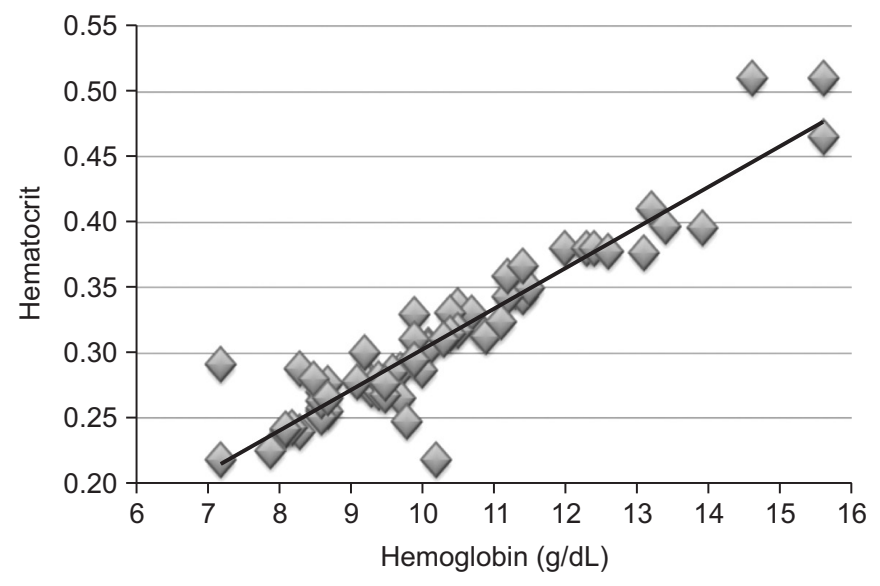

Fig. 1. Scatter plot of hemoglobin versus hematocrit at day 1 .



Fig. 2. Scatter plot of hemoglobin versus hematocrit at day 2.

following TKR.

Recognizing anaemia in patients following TKR is of particular importance due to the proven correlation between low $\mathrm{Hb}$ and reduced maximal exercise capacity ${ }^{13)}$. This has transcribed clinically with improved functional scores and shorter overall hospital stay in patients with higher $\mathrm{Hb}$ levels in the context of knee arthroplasty ${ }^{14)}$.

Transfusion rates following TKR continue to vary widely across the recent literature ranging from as low as $11 \%{ }^{15)}$ and reaching up to $29 \%{ }^{16}$. Our results demonstrated a transfusion rate of $8.2 \%$ based on the day $2 \mathrm{Hb}$ determinations. Research focusing on the degree of blood loss in the immediate postoperative period remains limited in the literature; however, there is evidence to suggest that over $80 \%$ of hemorrhage occurs in the first 12 hours following surgery with $94 \%$ occurring the following 24 hours ${ }^{17}$. Contrary to this, a study addressing postoperative swelling following TKR found swelling was most commonly representative 
of ongoing blood loss and this typically occurred from days 3 to $5^{18}$. This 'hidden' blood loss signifies a considerable issue in knee arthroplasty specifically and is thought to represent up to $58 \%$ of the measured blood loss ${ }^{19)}$. In both studies, ongoing $\mathrm{Hb}$ monitoring is recommended based on leg swelling and drain output; however, no formal timing for testing is advised.

Postoperative $\mathrm{Hb}$ determination following knee arthroplasty is conventionally carried out on day 1 following surgery. The $\mathrm{Hb}$ concentration can fall by up to $5.3 \mathrm{~g} / \mathrm{dL}$ immediately following surgery, highlighting the potential urgency for early determination over delayed testing. In such cases, however, we would argue that a large volume of intraoperative blood loss would have been obvious to the operating surgeon and resulted in the instigation of urgent postoperative $\mathrm{Hb}$ testing or even direct early transfusion. Furthermore, with acute significant drops in the $\mathrm{Hb}$ level, patients are more likely to become symptomatic, and therefore subsequently undergo blood testing and blood transfusion.

The majority of research into $\mathrm{Hb}$ and Hct determination following acute blood loss has largely taken place in the setting of acute trauma management. In this context, the $\mathrm{Hb}$ concentration is generally deemed to be inaccurate at defining the degree of acute blood loss ${ }^{20,21)}$. The role of the Hct level, however, is more controversial, with the traditional standpoint of Hct being a more sensitive indicator of acute blood loss than the Hb. The shift of fluid from the interstitial into the intravascular space in the physiological response to blood loss is thought to occur at a more rapid rate, making this parameter more useful over a shorter period of time ${ }^{20)}$. Our data, however, suggests the Hct tends to derange in correlation with the $\mathrm{Hb}$ concentration, which is in keeping with the findings of the analysis performed on a large series of trauma patients confirming identical behavior of these particular parameters $^{21)}$.

A significant limitation of the present study is the small patient numbers included in the analysis and the retrospective design. We would welcome future prospective studies addressing the question of timing for $\mathrm{Hb}$ determination following any arthroplasty surgery, specifically addressing $\mathrm{Hb}$ patterns at days 3 to 5 following the operation, as this is an area which has previously not been addressed in the literature.

Determination of the $\mathrm{Hb}$ concentration following knee arthroplasty is vital for preventing cardiorespiratory complications as well as improving rehabilitation potential. The timing for such testing remains controversial. Early determination may not truly reflect the degree of blood loss, with hidden blood loss further complicating the picture. Ongoing blood loss into a large joint space and within tissue planes is not uncommon in the initial period following a TKR; however, this is highly variable among patients.

\section{Conclusions}

Our study would support the requirement for routine testing at day 2. However, with small numbers used in the present analysis, we feel at this stage this recommendation should be limited to those patients in whom cardiorespiratory symptoms develop and those with progressive clinical knee and leg swelling. Patients should therefore be frequently reviewed in the initial 48 hours following surgery for the signs and symptoms of ongoing blood loss and anaemia.

The findings of our study also indicate that the Hct level does not provide any additional information over $\mathrm{Hb}$ determination alone following knee arthroplasty, which is in keeping with the current trend of the literature.

\section{Conflict of Interest}

No potential conflict of interest relevant to this article was reported.

\section{References}

1. Watts CD, Pagnano MW. Minimising blood loss and transfusion in contemporary hip and knee arthroplasty. J Bone Joint Surg Br. 2012;94(11 Suppl A):8-10.

2. Cordoba R, Tapia B, Aramburu O, Mora MA, Bielza R, Escalera J, Lora-Tamayo JI, Ercoreca L. Tranexamic acid reduces blood transfusion, postoperative blood loss and length of hospital stay in total knee arthroplasty. J Blood Disorders Transf. 2014;5:207.

3. Prasad N, Padmanabhan V, Mullaji A. Blood loss in total knee arthroplasty: an analysis of risk factors. Int Orthop. 2007;31:39-44.

4. Alcelik I, Pollock RD, Sukeik M, Bettany-Saltikov J, Armstrong PM, Fismer P. A comparison of outcomes with and without a tourniquet in total knee arthroplasty: a systematic review and meta-analysis of randomized controlled trials. J Arthroplasty. 2012;27:331-40.

5. Ajwani SH, Jones M, Jarratt JW, Shepard GJ, Ryan WG. Computer assisted versus conventional total knee replacement: a comparison of tourniquet time, blood loss and length of stay. Knee. 2012;19:606-10.

6. Ko PS, Tio MK, Tang YK, Tsang WL, Lam JJ. Sealing the 
intramedullary femoral canal with autologous bone plug in total knee arthroplasty. J Arthroplasty. 2003;18:6-9.

7. Calder L, Hebert PC, Carter AO, Graham ID. Review of published recommendations and guidelines for the transfusion of allogeneic red blood cells and plasma. CMAJ. 1997; 156:S1-8.

8. Murphy MF, Wallington TB, Kelsey P, Boulton F, Bruce M, Cohen H, Duguid J, Knowles SM, Poole G, Williamson LM; British Committee for Standards in Haematology, Blood Transfusion Task Force. Guidelines for the clinical use of red cell transfusions. Br J Haematol. 2001;113:24-31.

9. Hebert PC, Wells G, Blajchman MA, Marshall J, Martin C, Pagliarello G, Tweeddale M, Schweitzer I, Yetisir E. A multicenter, randomized, controlled clinical trial of transfusion requirements in critical care: Transfusion Requirements in Critical Care Investigators, Canadian Critical Care Trials Group. N Engl J Med. 1999;340:409-17.

10. Carson JL, Carless PA, Hebert PC. Outcomes using lower vs higher hemoglobin thresholds for red blood cell transfusion. JAMA. 2013;309:83-4.

11. Gonzalez-Porras JR, Colado E, Conde MP, Lopez T, Nieto MJ, Corral M. An individualized pre-operative blood saving protocol can increase pre-operative haemoglobin levels and reduce the need for transfusion in elective total hip or knee arthroplasty. Transfus Med. 2009;19:35-42.

12. Shimazaki M. Difference in hemoglobin concentration by timing of blood sampling in hemodialysis patients. Dial Transplant. 2009;38:350-3.

13. Woodson RD, Wills RE, Lenfant C. Effect of acute and established anemia on $\mathrm{O} 2$ transport at rest, submaximal and maximal work. J Appl Physiol Respir Environ Exerc Physiol. 1978;44:36-43.

14. Diamond PT, Conaway MR, Mody SH, Bhirangi K. Influence of hemoglobin levels on inpatient rehabilitation outcomes after total knee arthroplasty. J Arthroplasty. 2006;21: 636-41.

15. Carling MS, Jeppsson A, Eriksson BI, Brisby H. Transfusions and blood loss in total hip and knee arthroplasty: a prospective observational study. J Orthop Surg Res. 2015;10:48.

16. Vuille-Lessard E, Boudreault D, Girard F, Ruel M, Chagnon M, Hardy JF. Red blood cell transfusion practice in elective orthopedic surgery: a multicenter cohort study. Transfusion. 2010;50:2117-24.

17. Senthil Kumar G, Von Arx OA, Pozo JL. Rate of blood loss over 48 hours following total knee replacement. Knee. 2005; 12:307-9.

18. Gao FQ, Li ZJ, Zhang K, Huang D, Liu ZJ. Risk factors for lower limb swelling after primary total knee arthroplasty. Chin Med J (Engl). 2011;124:3896-9.

19. Sehat KR, Evans RL, Newman JH. Hidden blood loss following hip and knee arthroplasty: correct management of blood loss should take hidden loss into account. J Bone Joint Surg Br. 2004;86:561-5.

20. Ryan ML, Thorson CM, Otero CA, Vu T, Schulman CI, Livingstone AS, Proctor KG. Initial Hct in trauma: a paradigm shift? J Trauma Acute Care Surg. 2012;72:54-9.

21. Nijboer JM, van der Horst IC, Hendriks HG, ten Duis HJ, Nijsten MW. Myth or reality: Hct and hemoglobin differ in trauma. J Trauma. 2007;62:1310-2. 